3-14-2002

\title{
The Effect of the Thermal Barrier Coating on the Displacement Instability in Thermal Barrier Systems
}

Anette M. Karlsson

Cleveland State University, a.karlsson@csuohio.edu

T. Xu

Princeton University

A. G. Evans

Princeton University

Follow this and additional works at: https://engagedscholarship.csuohio.edu/enme_facpub

Part of the Mechanical Engineering Commons

How does access to this work benefit you? Let us know!

Publisher's Statement

NOTICE: this is the author's version of a work that was accepted for publication in Acta

Materialia. Changes resulting from the publishing process, such as peer review, editing, corrections, structural formatting, and other quality control mechanisms may not be reflected in this document. Changes may have been made to this work since it was submitted for publication. A definitive version was subsequently published in Acta Materialia, 50, 5, March 14, 2002; 10.1016/S1359-6454(01)00422-0

\section{Original Citation}

Karlsson, A., Xu, T., and Evans, A., 2002, "The Effect of the Thermal Barrier Coating on the Displacement Instability in Thermal Barrier Systems," Acta Materialia, 50(5) pp. 1211-1218.

This Article is brought to you for free and open access by the Mechanical Engineering Department at EngagedScholarship@CSU. It has been accepted for inclusion in Mechanical Engineering Faculty Publications by an authorized administrator of EngagedScholarship@CSU. For more information, please contact library.es@csuohio.edu. 


\title{
The effect of the thermal barrier coating on the displacement instability in thermal barrier systems
}

\author{
A.M. Karlsson *, T. Xu, A.G. Evans \\ Princeton Materials Institute, Princeton University, Princeton, NJ 08540-5211, USA
}

\section{Introduction}

Thermal barriers are commonly used on hightemperature components in turbine engines. They comprise the following multilayers: (i) the superalloy substrate, (ii) the bond coat, (iii) the thermally grown oxide (TGO), and (iv) the thermal barrier coating (TBC). Measurements, observations and simulations performed on such thermal barrier systems have addressed the instability of the TGO subject to thermal cycling [1-11]. The phenomenon has been most extensively addressed in connection with the durability of TBCs made by electron beam-physical vapor deposition (EB-PVD) on

\footnotetext{
* Corresponding author.

E-mail address: karlsson@princeton.edu (A.M. Karlsson).
}

a Pt-modified diffusion aluminide bond coat. In such cases, the instability appears as a penetration of the TGO into the underlying alloy (the bond coat), which results in cracks in the superposed TBC that extend laterally as the system cycles. These cracks eventually coalesce and cause failure of the TBC by large-scale buckling [9,11-13]. The incidence of cracking within the TBC differentiates such failures from those occurring between the TGO and the bond coat [4]. The experimental evidence for this instability is unambiguous $[2,7,9$ 12 ], as is its association with imperfections on the bond coat surface prior to deposition of the TBC $[11,12,15]$. Removal of initial imperfections by planarizing the bond coat surface suppresses the instability, resulting in enhanced durability [12].

A scheme for numerical simulation of the instability has been developed $[3,6,8]$. It embodies four 
interactive strains; all are essential to duplication of the experimental findings. These are the elastic and plastic strains, as well as two misfit strains: one induced by growth of the TGO and the other by the thermal contraction/expansion upon cooling and reheating.

Prior simulations have neglected the TBC layer. This deficiency is addressed here by performing calculations for a system that includes an EB-PVD material having prototypical mechanical properties, with and without cracks.

\section{Characteristics of the thermal barrier coating}

All commercial TBCs have anisotropic properties caused by microstructural heterogeneities, such as oriented cracks and separations [1,2,9-11]. These provide the strain tolerance essential to the avoidance of instantaneous delamination. A basic modeling challenge concerns the scale of the microstructural heterogeneities relative to features that nucleate and propagate failure. The observations $[7,11]$ indicate that the heterogeneities must be modeled discretely. For this to be accomplished, representative problems must be posed. The objective is to establish a representation having sufficient simplicity to enable meaningful simulations without excluding critical phenomena. For TBCs made by EB-PVD, the coating is considered to incorporate zero traction planes that represent segments of the TBC disconnected from others, because of conditions that prevail as it deposits. The conical region depicted in Fig. 1 is typical $[7,11,15]$.

The explicit strategy is as follows. Preliminary calculations are performed using a homogeneous TBC with Young's modulus in the range $0 \leq E_{\mathrm{tbc}} \leq 40 \mathrm{GPa}$ [13]. The stresses induced in the TBC are evaluated, as well as the cyclic displacements. Then, some consequences of orthotropy on the stresses and displacements are explored. Thereafter, calculations are conducted subject to traction-free internal surfaces (Fig. 1), comprising a conical zone of converging columnar grains, known to be coincident with TGO instability sites $[7,11,12]$.
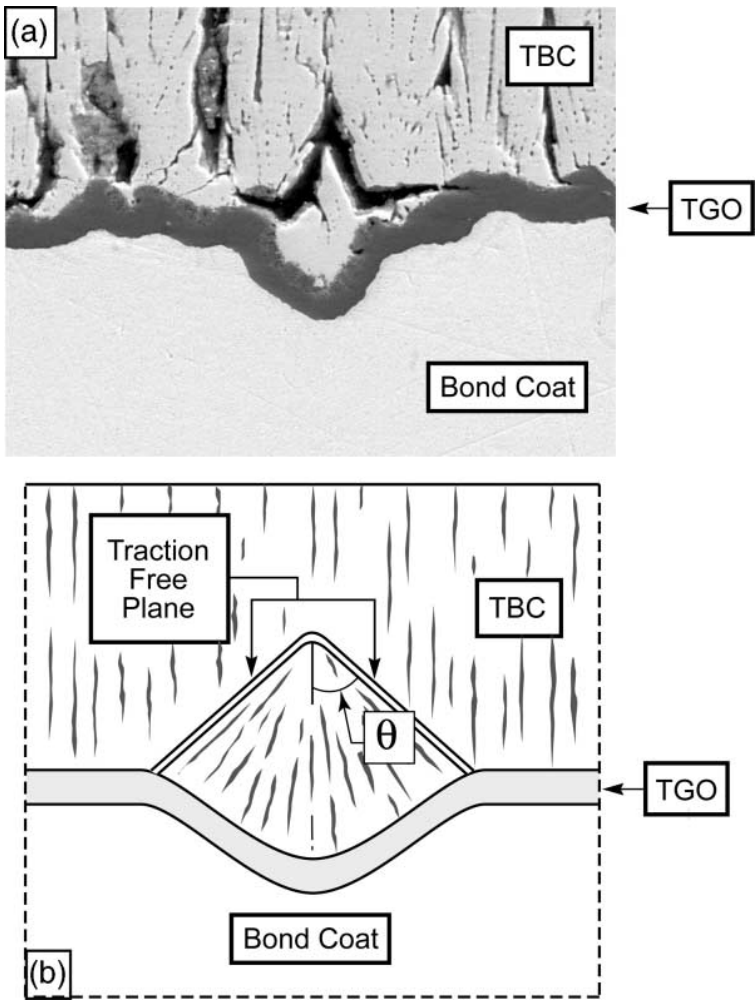

Fig. 1. (a) Typical "pinched-off" cone in TBC after thermal cycling (courtesy D.R. Mumm). (b) The cone is modeled with traction-free planes.

\section{Simulations}

\subsection{The model}

The basic material characteristics are unchanged from those elaborated elsewhere (Table 1) $[6,8]$. The only substantive difference is the superposition of a TBC having properties that duplicate measurements and observations [13]. It remains elastic, except for the presence of microstructurally-related zero traction planes. The finite element model used to conduct the calculations is shown in Fig. 2.

Calculations are performed by invoking a temperature-invariant bond coat yield strength, $\sigma_{\mathrm{Y}}^{\text {bc }}$. Results will be presented for $\sigma_{\mathrm{Y}}^{\text {bc }}$ in the range 200 $400 \mathrm{MPa}$. Previous calculations conducted with a more representative temperature-dependent yield condition [6], with very low strength at the highest 
Table 1

Summary of material properties used in the model

\begin{tabular}{|c|c|c|c|c|}
\hline & $\begin{array}{l}\text { Young's modulus } \\
\text { (GPa) }\end{array}$ & Yield stress (GPa) & Poisson ratio & $\begin{array}{l}\text { Thermal expansion } \\
\text { coefficient }\left(\mathrm{ppm}^{\circ} \mathrm{C}\right)\end{array}$ \\
\hline TBC & $5-40$ & Elastic & 0.3 & 11 \\
\hline TGO & 380 & $\begin{array}{l}T \geq 1000{ }^{\circ} \mathrm{C}: 1.0 \\
T<900{ }^{\circ} \mathrm{C}: 10.0\end{array}$ & 0.2 & 8 \\
\hline Bond coat & 190 & $0.2-0.4$ & 0.3 & 14 \\
\hline Substrate & 190 & Elastic & 0.3 & 14 \\
\hline
\end{tabular}

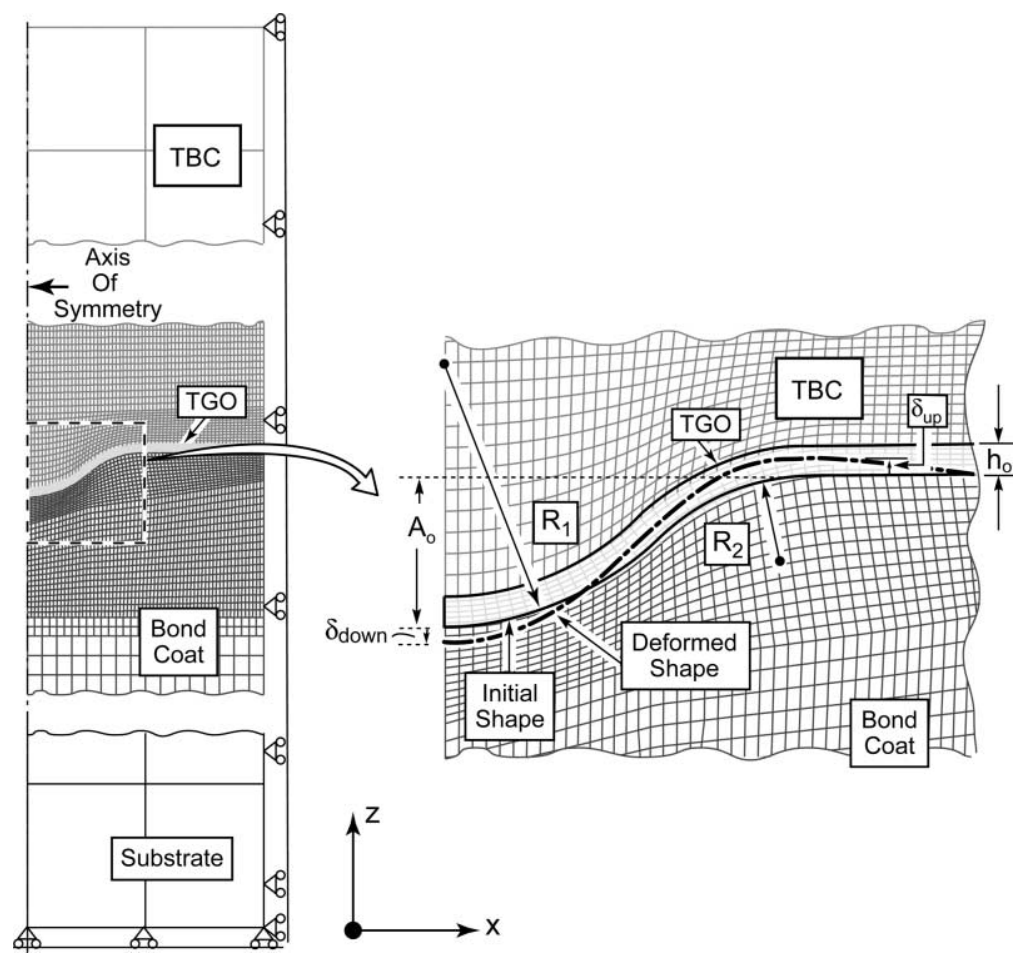

Fig. 2. Finite element model including the TBC, TGO, BC and substrate.

temperature, have indicated that the instability is duplicated fairly well by using yield strengths in this range. Moreover, by asserting that the yield strength is that measured at strain rates comparable to those involved in thermal cycling, recent assessments of the creep response [16] have indicated that there are no additional time dependencies.

The initial simulations are performed with a ratio of growth to thickening strain in the TGO, $\beta=0.1[6,8]$. The TGO is allowed to yield at the temperature maximum, restricting the growth stress to $\pm 1 \mathrm{GPa}[6]$ : otherwise, it is elastic. ${ }^{1}$ Table 1 summarizes the material properties used in the model. The system is thermally cycled between 0 and $1000{ }^{\circ} \mathrm{C}$, for 24 cycles, causing the TGO to increase in thickness from 0.5 to $0.62 \mu \mathrm{m}$. Note that the TGO thickness at failure for representative

\footnotetext{
${ }^{1}$ This is done by letting $\sigma_{\mathrm{Y}}^{\text {tgo }}=10 \mathrm{GPa}$ for $T<900{ }^{\circ} \mathrm{C}$, $\sigma_{\mathrm{Y}}^{\text {tgo }}=1 \mathrm{GPa}$ for $T>1000^{\circ} \mathrm{C}$, and letting $\sigma_{\mathrm{Y}}^{\text {tgo }}$ vary linearly in between.
} 
commercial TBC systems is 5-6 $\mu \mathrm{m}[7,9,11,12]$. Accordingly, the present simulations represent a small fraction of the lifetime of the system.

The initial imperfection in the bond coat is axisymmetric and characterized by two radii of curvature: concave at the center of symmetry, $R_{1}$, and convex at the perimeter, $R_{2}$ [6]. The ratio of these radii is varied between $R_{2} / R_{1}=0.05$ and 0.9 .

\subsection{General response}

Initial results are generated for an intact TBC with isotropic elastic properties, having a modulus in the range $0 \leq E_{\mathrm{tbc}} \leq 40 \mathrm{GPa}$ [13]. Results for $\sigma_{\mathrm{Y}}^{\mathrm{bc}}=200$ and $400 \mathrm{MPa}$ will be presented, as discussed above. A synopsis of the major findings is presented in Figs. 3-5. As the modulus of the TBC increases, the displacement of the TGO per cycle decreases (Fig. 3). The $\sigma_{z z}$ stress in the TBC, responsible for delamination and failure, is tensile in a zone above the instability site (Fig. 4). This zone expands as the system cycles, because of the combined effects of TGO growth, thermal expansion misfit and bond coat yielding. After 24 cycles, it extends into the TBC a distance about equal to the imperfection amplitude. Within a single cycle, this stress is relatively unaltered by the temperature change between 0 and $1000{ }^{\circ} \mathrm{C}$. When sufficiently

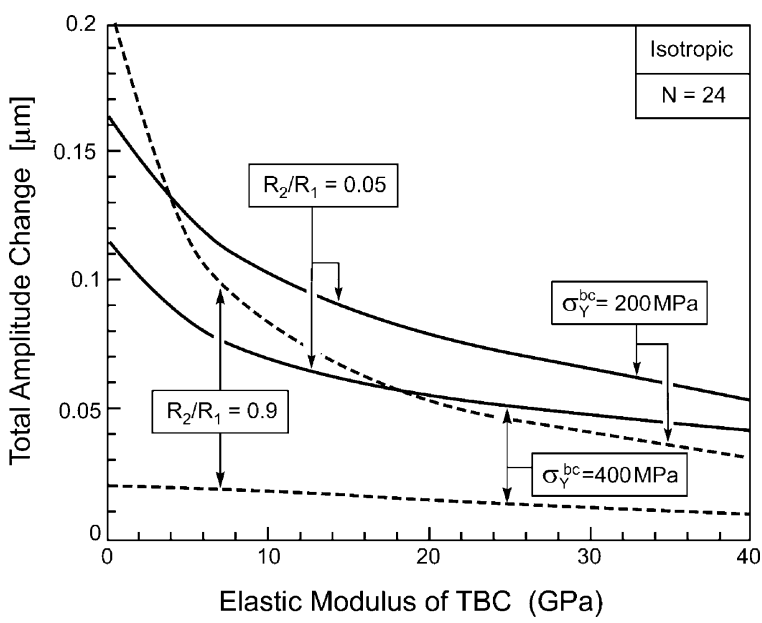

Fig. 3. The total amplitude change after 24 cycles as a function of the elastic modulus in the TBC (isotropic). The graph shows that the TBC can dampen the amplitude change significantly.

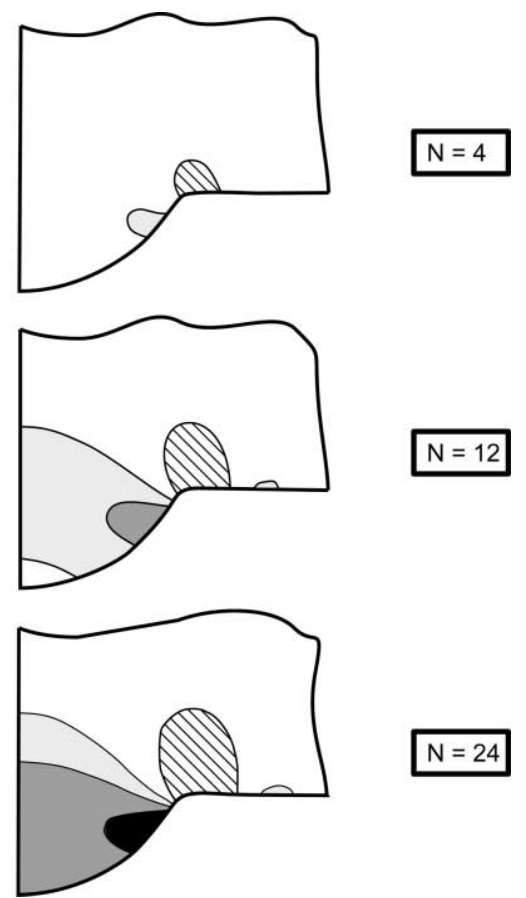

Fig. 4. The development of out-of-plane stresses in the TBC. The large tensile stresses above the instability site suggest likely locations for cracks to initiate and develop (isotropic TBC, $\left.E_{\mathrm{TBC}}=20 \mathrm{GPa}, \sigma_{\mathrm{Y}}^{\mathrm{bc}}=200 \mathrm{MPa}, R_{2} / R_{1}=0.05\right)$.

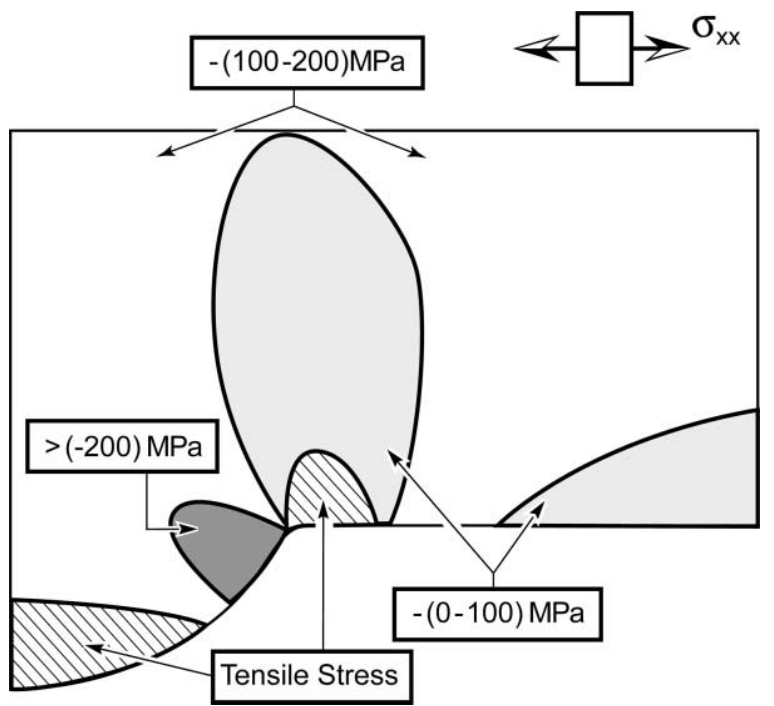

Fig. 5. The in-plane stresses associated with the final stage of failure are primarily compressive (after 24 cycles, isotropic $\left.\mathrm{TBC}, E_{\mathrm{TBC}}=20 \mathrm{GPa}, \sigma_{\mathrm{Y}}^{\mathrm{bc}}=200 \mathrm{MPa}, R_{2} / R_{1}=0.05\right)$. 
large, it motivates the cracks observed in the TBC above the instabilities and causes them to extend laterally $[7,11,12]$. The modified response, once a crack has formed, is discussed in the following section. Beyond this zone, there are small regions of compression and tension caused by bending of the TGO.

The ambient in-plane compression, $\sigma_{x x}$, which affects the final stages of failure through its role in large-scale buckling [14], is depicted in Fig. 5. Note that the compression is fairly uniform except for zones of localized tension around the imperfection. The latter could influence crack nucleation by interacting with the $\sigma_{z z}$ stress.

The effects of TBC orthotropy are addressed next. To be representative of EB-PVD materials, the simulations assume an out-of-plane modulus, $E_{z z}=200 \mathrm{GPa}$, pertinent to fully dense $\mathrm{ZrO}_{2}$, with an in-plane modulus that varies in the range $0 \leq E_{x x} \leq 40 \mathrm{GPa}$. Results are shown in Fig. 6, where they are compared with those for the isotropic TBC. Note that the large $E_{x x}$ suppresses the displacement once $E_{x x} \geq 5 \mathrm{GPa}$. The implication is that, without cracks and separations in the TBC, the presence of the TBC prevents the TGO instability.

The role of the TBC stiffness in suppressing the instability should not be interpreted as an indi-

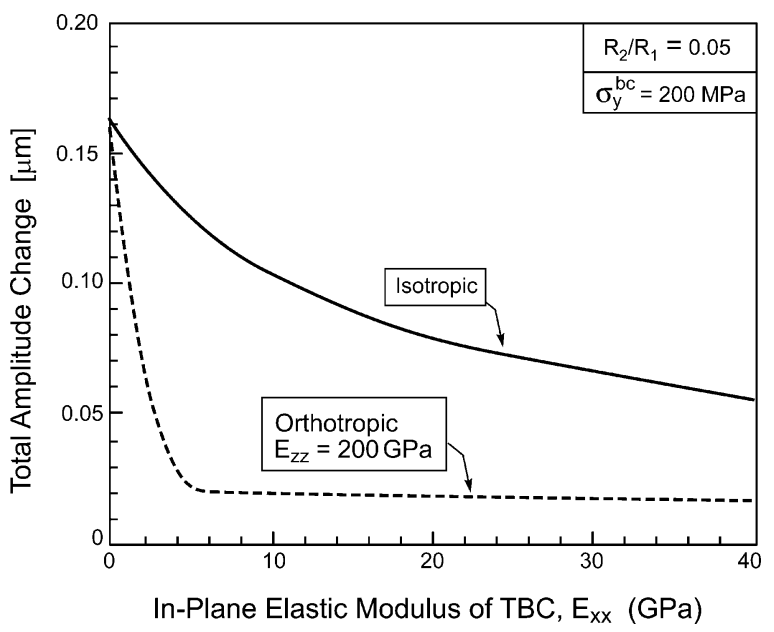

Fig. 6. The total amplitude change after 24 cycles, as a function of the in-plane elastic modulus, for an orthotropic TBC. The orthotropy diminishes the amplitude change $\left(\sigma_{\mathrm{Y}}^{\mathrm{bc}}=200\right.$ $\left.\mathrm{MPa}, R_{2} / R_{1}=0.05\right)$. cation that increasing the TBC stiffness necessarily increases the system's durability. Indeed, some inplane compliance is needed for strain tolerance, because the energy density in the TBC caused by thermal expansion misfit increases as the stiffness becomes larger, causing the TBC to fail by edge delamination [15]. Accordingly, the role of the TBC relates to its effect on localization of the instability, as discussed next.

\subsection{Traction-free plane}

Crack-like defects that pre-exist in the TBC (Fig. 1) $[7,11,12]$ are modeled as a traction-free plane at the perimeter of the cone, defined by the included angle $\theta$ (Fig. 1). While simulations have been performed for a range of radius ratios, only the results for $R_{2} / R_{1}=0.05$ will be presented. Other ratios exhibit similar behavior. Similarly, while ranges of geometries and included angles have been investigated, the discussion will be limited to $\theta=40^{\circ}$ and $70^{\circ}$ for brevity. The simulations of the displacements after 24 cycles (Fig. 7) reveal that the amplitude changes are larger than those for an intact $\mathrm{TBC}$, with the larger displacement rate occurring at the larger angle.

The $\sigma_{z z}$ stress at ambience is dramatically altered by the introduction of the traction-free plane (Fig. $8 a, b)$. Note that the tensile stress over the insta-

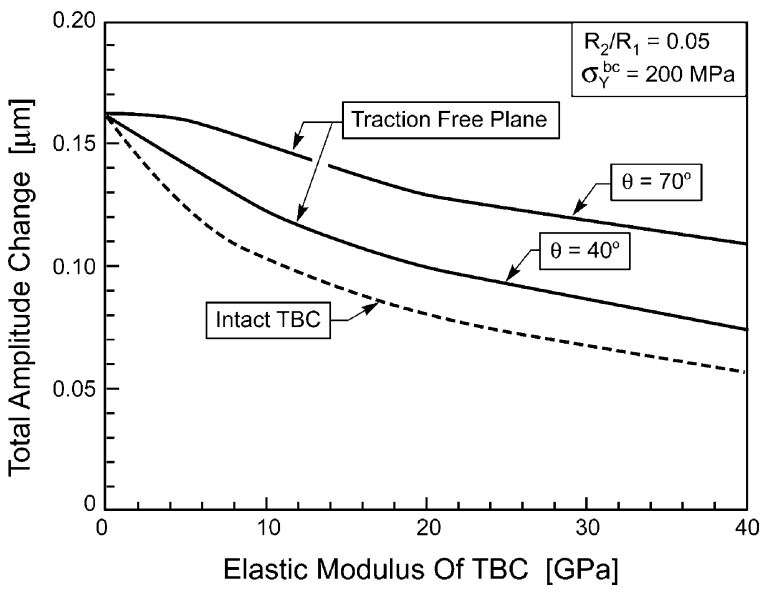

Fig. 7. The effect of traction-free planes in the TBC on the total amplitude change as a function of the elastic modulus. Note that the amplitude change exceeds that for an intact TBC. (Isotropic TBC, $E_{\mathrm{TBC}}=20 \mathrm{GPa}, \sigma_{\mathrm{Y}}^{\mathrm{bc}}=200 \mathrm{MPa}, R_{2} / R_{1}=0.05$.) 
(a) Intact TBC, 24 cycles

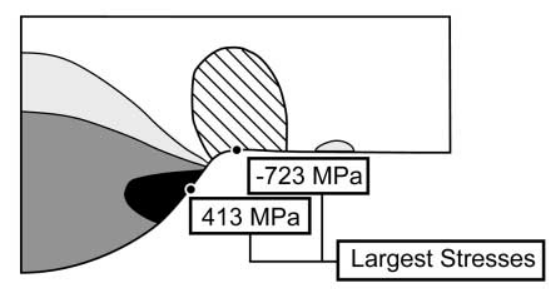

\begin{tabular}{|l|l|}
\hline (b) & Traction Free Plane, 24 cycles \\
\hline
\end{tabular}

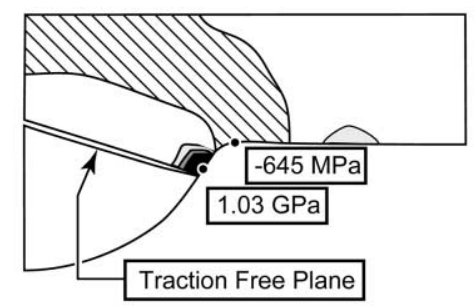

\section{(c) Intact TBC, single cycle}

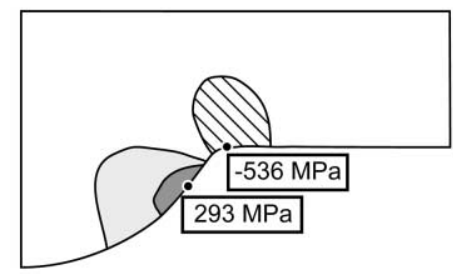

\begin{tabular}{|l|l|}
\hline (d) & Traction Free Plane, single cycle \\
\hline
\end{tabular}

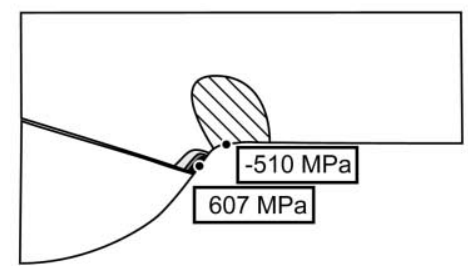

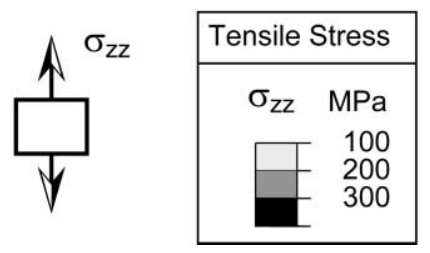

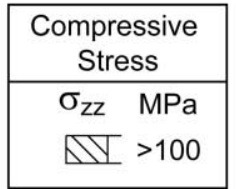

Fig. 8. The out-of-plane stresses, $\sigma_{z z}$, in the TBC. (a) Intact TBC after 24 cycles. (b) TBC with traction-free plane after 24 cycles. (c) Intact $\mathrm{TBC}$ after a single cycle. (d) $\mathrm{TBC}$ with traction-free plane after a single cycle. (Isotropic $\mathrm{TBC}, E_{\mathrm{TBC}}=20 \mathrm{GPa}, \sigma_{\mathrm{Y}}^{\mathrm{bc}}=200$ $\mathrm{MPa}, R_{2} / R_{1}=0.05$.)

bility site has been relieved and has devolved into a stress concentration around its tip, adjacent to the TGO. This stress concentration is believed to be the motivation for lateral extension of the TBC crack shown in Fig. 1a $[7,11,12]$. In a future study, the associated energy release rate will be used to simulate lateral extension of the defect into a delamination crack.

The separation of the faces of the traction-free plane (Figs. 8 and 9) dictate the increased rate of growth of the instability. This finding reveals that the instability of the TGO occurs preferentially either in regions where traction-free planes exist in the TBC or where cracks form because of the induced tensile stresses.

\subsection{Sensitivity study}

A sensitivity analysis is conducted to gain further insight into parameters influencing the instability. Based on the findings of a related analysis performed without the TBC $[6,8]$, the variables to be explored include the ratio of in-plane to thickening strains in the TGO, $\beta$, followed by a comparison between isothermal and cyclic conditions. Only the results for $R_{2} / R_{1}=0.05$ are discussed.

The cyclic shape distortion for the TBC with a traction-free plane is depicted in Fig. 9 for various $\beta$, at a fixed thickening strain, $\varepsilon_{\mathrm{t}}$. Note the systematic increase in the opening of the separation in the 


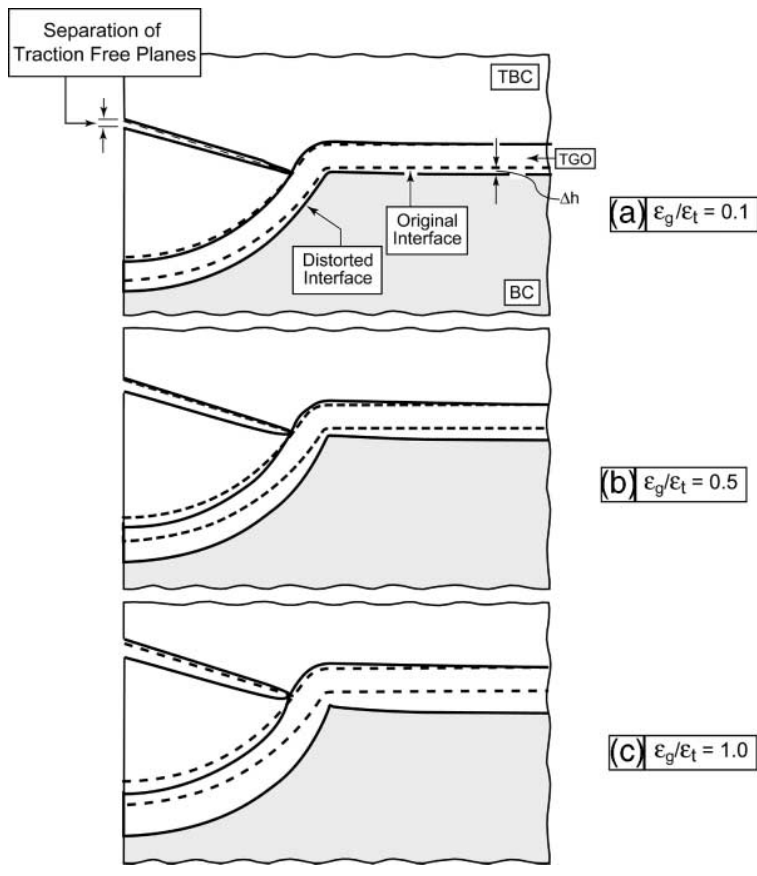

Fig. 9. The change in shape of the TBC/TGO/BC and the opening of the traction-free plane after thermal cycling for various TGO growth strains. (a) $\varepsilon_{\mathrm{g}} / \varepsilon_{\mathrm{t}}=0.1$, (b) $\varepsilon_{\mathrm{g}} / \varepsilon_{\mathrm{t}}=0.5$, (c) $\varepsilon_{\mathrm{g}} / \varepsilon_{\mathrm{t}}=1.0$. (Isotropic TBC, $E_{\mathrm{TBC}}=20 \mathrm{GPa}, \sigma_{\mathrm{Y}}^{\text {bc }}=200 \mathrm{MPa}$, $R_{2} / R_{1}=0.05$.)

TBC as $\beta$ increases, as well as the corresponding increase in the amplitude of the imperfection. Moreover, larger changes in amplitude occur as the relative amount of internal TGO growth increases (Fig. 10a).

In the absence of the $\mathrm{TBC}$, some of the growth strain is redistributed to thickening [8]. This effect is less apparent in the presence of the TBC, because the constraint tends to unify the stress. Consequently, the thickness of the TGO after thermal cycling is almost uniform (Fig. 10b), consistent with experimental observations [7,11,12].

For isothermal simulations, the material is held at a temperature long enough to accumulate the same growth strain as that acquired upon thermal cycling, then cooled to ambient and reheated. The $\sigma_{z z}$ stresses with and without a traction-free plane (Fig. 8) are much lower than those upon cycling. Moreover, the isothermal amplitude change is substantially smaller (Fig. 11), consistent with the

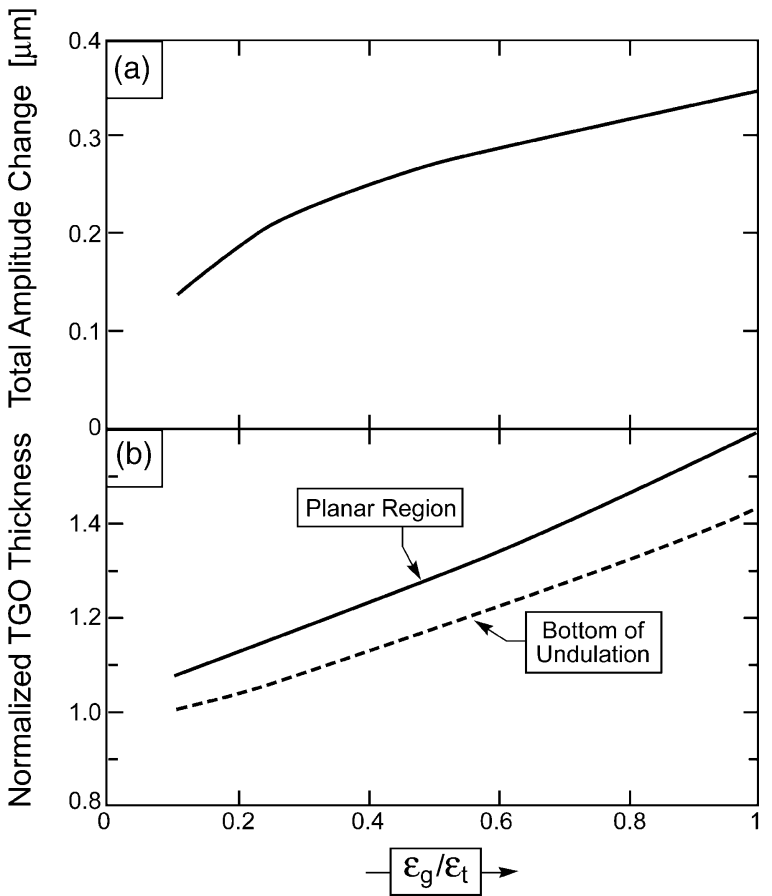

Fig. 10. (a) The total amplitude change after 24 cycles as a function of TGO growth strain. (b) The thickness of the TGO after 24 cycles as a function of the growth strain. (Isotropic $\mathrm{TBC}, E_{\mathrm{TBC}}=20 \mathrm{GPa}, \sigma_{\mathrm{Y}}^{\mathrm{bc}}=200 \mathrm{MPa}, R_{2} / R_{1}=0.05$.)

response in the absence of the TBC $[6,8]$, and with experimental observations $[7,11,12]$.

\section{Conclusion}

Numerical simulations have been performed to elucidate parameters governing displacement instabilities in thermal barrier systems with an EB-PVD TBC and a Pt-aluminide bond coat. Simulations have been performed for a homogeneous TBC and for a defective material with traction-free planes. The latter represent conical imperfections, where the material near the interface is disconnected from the rest of the TBC. The instabilities develop preferentially in regions containing such defective domains. The constraint when the TBC is intact restricts instability development. Even in this case, the induction of high local stresses suggests that cracks initiate and develop in the TBC near the 

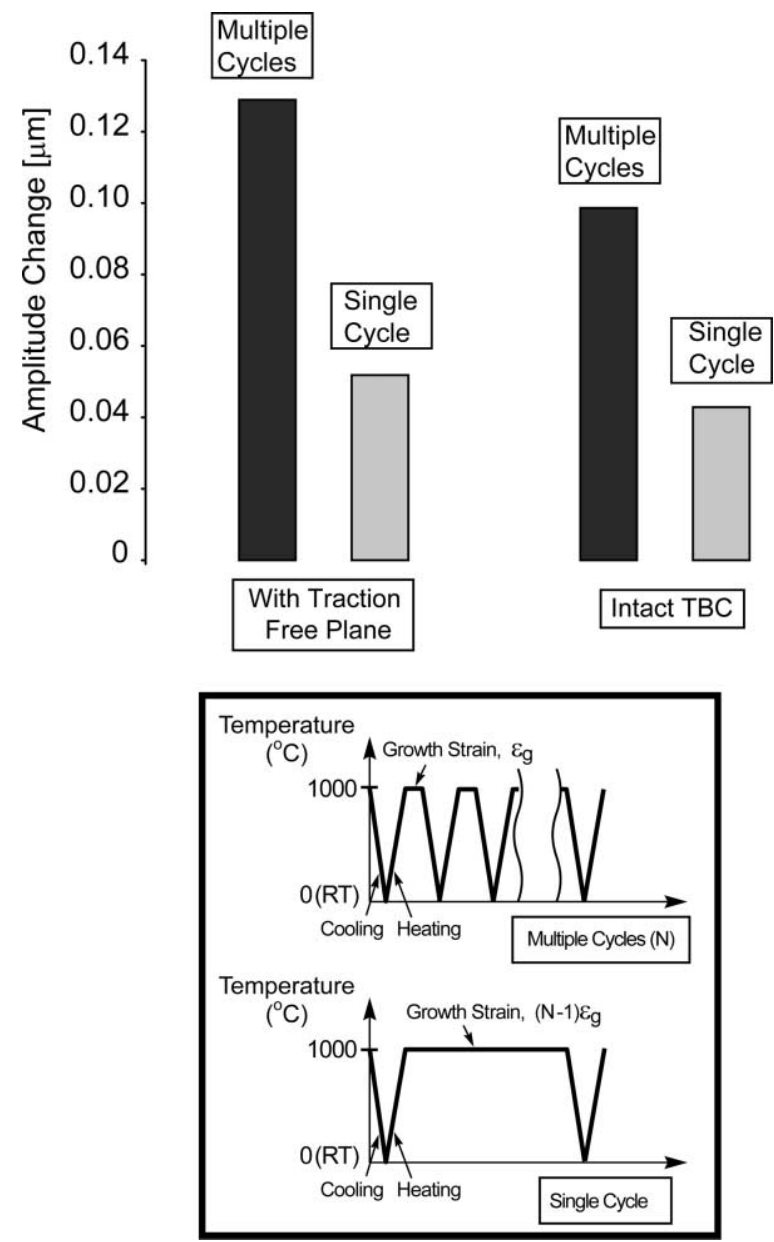

Fig. 11. Comparing the total amplitude change after 24 cycles to that after a single cycle, for the same TGO growth, reveals that cycling accelerates the amplitude change. (Isotropic TBC, $E_{\mathrm{TBC}}=20 \mathrm{GPa}, \sigma_{\mathrm{Y}}^{\mathrm{bc}}=200 \mathrm{MPa}, R_{2} / R_{1}=0.05$.

interface [7] and, thereafter, facilitate the development of local instability.

Two classes of sensitivity studies have been per- formed. The first varied the ratio of the lengthening-to-thickening component of the TGO growth strain and demonstrated that the TBC constraint results in greater uniformity in the TGO thickness than in studies performed without the TBC. In the second, it was shown that, for the same overall increase in TGO thickness, the cyclic amplitude changes are appreciably larger than those that arise isothermally, in accordance with experimental findings [11].

\section{References}

[1] Wright PK, Evans AG. Curr Opin Solid State Mater Sci 1999;4:255-65.

[2] Gell M, Vaidyanathanm K, Barber B, Cheng J, Jordan E. Metall Mater Trans 1999;30A:427-35.

[3] He MY, Evans AG, Hutchinson JW. Acta Mater 2000;48:2593-601.

[4] Mumm DR, Evans AG. Acta Mater 2000;48:1815-27.

[5] Ambrico JM, Begley MR, Jordan EH. Acta Mater 2001;49:1577-88.

[6] Karlsson AM, Evans AG. Acta Mater 2001;49:1793-804.

[7] Mumm DR, Evans AG, Spitsberg I. Acta Mater 2001;49:2329-40.

[8] Karlsson AM, Levi CG, Evans AG. Effects of morphology and growth strain on displacement instabilities during cyclic thermal oxidation of bond coat alloys. Acta Mater (in press).

[9] Evans AG, Mumm DR, Hutchinson JW, Meier GH, Pettit FS. Prog Mater Sci 2001;46:505-53.

[10] Tolpygo V, Clarke DR. Acta Mater 2000;48:3283-93.

[11] Ruud JA, Bartz A, Borom MP, Johnson CA. J Am Ceram Soc 2001;84:1545-52.

[12] Spitsberg I, Mumm DR, Evans AG. Acta Mater (submitted for publication).

[13] Johnson CA, Ruud JA, Bruce R, Wortman D. Surf Coat Technol 1998;109:80-5.

[14] Choi SR, Hutchinson JW, Evans AG. Mech Mater 1999;31:431-47.

[15] Rebello N, Levi CG. (submitted for publication).

[16] Hemker K. Johns Hopkins University, unpublished research. 